\title{
A morte, musa da filosofia
}

\author{
Maria Lucia Cacciola
}

\section{RESUMO}

FIM Último DA VIDA DO INDIVÍdUO E NÃO DA ESPÉCIE, A MORTE NÃO SIGNIFICA PARA SCHOPENHAUER O FIM DA VontADE ENQUANTO ESSÊNCIA, ISTO É, DO QUERER-VIVER INDESTRUTíveL. A VISÃO DA MORTE COMO "MUSA DA FILOSOFIA" E DA FILOSOFIA COMO "PREPARAÇÃO PARA A MORTE" LIGA-SE À IMPORTÂNCIA DO ORGANISMO E DE SEU CICLO VITAL NO PENSAMENTO DO FILÓSOFO. ESSE SERÁ O PONTO DE PARTIDA PARA MOSTRAR A INTERDEPENDÉNCIA DE SUAS REFLEXÕES SOBRE A ÉTICA E, ACIMA DE TUDO, DA SUA CONDENAÇÃO DO SUICÍDIO, EM RELAÇÃO À SUA METAFÍSICA IMANENTE DA VONTADE COMO QUERER-VIVER, INCONTROLÁVEL PELO ARBÍTRIO INDIVIDUAL. DESSE MODO, UMA TAL "FILOSOFIA DA NATUREZA" MOSTRA O SEU PRESSUPOSTO: A IMPOSSIBILIDADE DE CONTROLE, POR QUALQUER INSTÂNCIA EXTERIOR, DESSE IMPULSO PRIMORDIAL. EM CONTRAPARTIDA, PÕE-SE A DIFERENÇA ABISSAL ENTRE A MORTE DO INDIVÍDUO E A NEGAÇÃO DA ATIVIDADE DA VONTADE.

\section{ABSTRACT:}

FINAL END OF LIFE OF THE INDIVIDUAL, NOT OF SPECIES, DEATH DOES NOT MEAN FOR SCHOPENHAUER THE END OF THE WILL AS ESSENCE, THAT IS, OF THE INDESTRUCTIBLE WILL-TO-LIVE. THE CONCEPTION OF DEATH AS "MUSE OF PHILOSOPHY", AND OF PHILOSOPHY AS "PREPARATION TO DEATH", IS RELATED TO THE IMPORTANCE OF THE ORGANISM AND ITS VITAL CYCLE IN SCHOPENHAUER'S THOUGHT. THIS WILL BE OUR STARTING POINT TO SHOW THE INTERDEPENDENCE BETWEEN HIS REFLECTIONS ON ETHICS, ABOVE ALL HIS REPROOF OF SUICIDE, AND HIS IMMANENT METAPHYSICS OF THE WILL AS WILL-TO-LIVE, UNCONTROLLABLE BY INDIVIDUAL CHOICE. SUCH A "PHILOSOPHY OF NATURE" SHOWS THEREBY ITS PRESUPPOSITION: THE IMPOSSIBILITY OF ANY EXTERNAL INSTANCE TO CONTROL THIS PRIMEVAL IMPULSE. ON THE OTHER HAND, THERE IS A HUGE DIFFERENCE BETWEEN INDIVIDUAL DEATH AND THE DENIAL OF THE ACTIVITY OF THE WILL.

Filosofia da negação ou releitura do limites impostos ao humano quanto à sua possibilidade de conhecer desde Kant: eis as duas alternativas que se impõem ao leitor de Schopenhauer.

Sua afirmação da imanência da filosofia, isto é, a sua atinência ao Mundo, seja enquanto Vontade que nele se manifesta, seja como representação do que nele se passa, dá a diretriz para sua leitura dos textos de Kant. Vê-se aqui ecoar a questão kantiana da utilidade apenas negativa da filosofia crítica que, para além dela, faz ver ao exame mais atento o alvo central do processo critico, a saber, o seu lado positivo, ao deixar em aberto um espaço, embora vazio, para o pensamento de algo inatingível pela humana faculdade de conhecimento, mas ao alcance do pensamento: os supremos interesses do homem, acima de qualquer ciência - as questões morais e metafísicas. Ora, a leitura do elemento negativo presente na filosofia schopenhauriana - deixemos um pouco de lado o conteúdo tão cheio de significados da palavra "niilista" -, seja como postura cética moral, seja como ausência de sentido da vida do indivíduo

"Professora Doutora do Departamento de Filosofia da FFLCH-USP. 
no seu contínuo nascer e perecer (o que, no caso de Schopenhauer, conduz até mesmo à idéia de aniquilação do mundo como vontade), talvez oculte, num paralelo com Kant, uma positividade: a proibição da transcendência, a restrição do homem à sua qualidade de organismo, abrindo, embora numa outra direção, um espaço para o significado moral, não mais transcendente e que ora se expõe na vontade imanente ao mundo, sua essência verdadeira. Assim, a interpretação da filosofia de Schopenhauer como volta à etapa pré-crítica ficaria revogada nessa recusa da transcendência, impondo-se, segundo a sua própria letra, um "dogmatismo" imanente. Os limites do mundo se expressam no próprio mundo, considerado nos seus dois aspectos: a vontade e a representação como perspectivas necessariamente complementares. ${ }^{1}$

"A morte, musa da filosofia", vem ao encontro desse feitio da filosofia de Schopenhauer, pois elege um sentimento originado num fenômeno natural, próprio da evolução do organismo, como inspirador da reflexão filosófica. A seu favor, Schopenhauer cita Platão, que, no Fedro, define a filosofia como "inquietude da morte", inquietude ou temor que invoca a reflexão filosófica. Schopenhauer atribui tal disposição à própria consciência humana, àquilo que distingue os homens do animal; este goza da "eternidade da espécie", confundindo-se com ela, mas no indivíduo humano surge, em contrapartida, com o desenvolvimento cerebral e da correspondente função intelectual, o temor da aniquilação, podendo servir-lhe de antídoto tanto a religião como a filosofia.

Mas é preciso distinguir entre religião e filosofia. Se os deuses nascem do temor da morte, sua origem é atribuída à promessa, em geral incluída nas religiões, de uma vida futura que venha tomar o lugar dessa vida mundana de sofrimentos inevitáveis. Schopenhauer mencio-

\footnotetext{
${ }^{1}$ Schopenhauer, A. Sämtliche Werke, vol. II. Darmstadt: Ed Löneysen WBG, 1974, p. 821-2: "A filosofia imanente no sentido kantiano da palavra", como Schopenhauer se referia ao seu pensamento, "não se empenha em explicar até os seus últimos fundamentos a existência do mundo: detém-se, ao contrário, nos fatos da experiência externa e interna, tais como são acessíveis a cada um, e aí mostra seu encadeamento profundo e verdadeiro, sem jamais ultrapassá-los para chegar até as coisas exteriores ao mundo e às relações que estas possam ter com ele. Ela não tira portanto nenhuma conclusão sobre o que existe além da experiência de toda experiência possível; não explica senão aquilo que é dado no mundo exterior e na própria consciência e contenta-se assim de abarcar a essência do mundo e a sua conexão íntima com ele".
} 
na a pouca importância ou falta de credibilidade que seria dada a religiões que não oferecem tal consolo. "Se fosse provada a total impossibilidade de uma vida imortal, desapareceria o interesse pela existência dos deuses", dando lugar a uma indiferença, que seria resultado da desesperança de um conhecimento mais íntimo deles. Ao contrário se a imortalidade fosse provada incompatível com a existência dos deuses, todos ansiariam por se tornarem ateus. ${ }^{2}$ Ao destacar a importância da refutação kantiana das provas da existência de Deus, Schopenhauer relembra ainda uma outra prova, esquecida por Kant: a keraunológica, baseada no pavor. A filosofia, e especialmente a metafísica, distinguem-se da religião por tratarem do tema da existência do homem e do mundo de modo racional; mas, por terem acesso apenas aos mais esclarecidos, admitem ao seu lado, para o homem comum, a religião como metafísica alegórica.

Ambas espécies de metafísica, que, em suma, diferem entre si como doutrina de convicção e doutrina de fé, têm em comum o fato de que cada sistema particular delas mantém uma relação de inimizade com as outras da sua espécie. As da primeira espécie guerreiam entre si só com palavras e escritos; as da outra, também com fogo e espada. ${ }^{3}$

Mas falar de metafísica impõe que se esclareça seu conceito para o filósofo. Ao abandonar a filosofia transcendente, em prol de um significado imanente, Schopenhauer invoca Kant e a crítica aos dogmatismos anteriores. No capítulo 50 dos Suplementos ao Mundo, afirma que a sua filosofia, tal como a de Kant,

não se empenha em explicar até os últimos fundamentos a existência do mundo: seu ponto de parada são os fatos da experiência externa e interna, tais como acessíveis a cada um, onde se mostra seu encadeamento profundo e verdadeiro, sem jamais ultrapassá-los para chegar até as coisas exteriores ao mundo e

\footnotetext{
${ }^{2}$ Idem, p. 208.

${ }^{3}$ Idem, p. 213.
} 
às relações que possam ter com ele. Não tira assim nenhuma conclusão sobre o que existe além de toda experiência possível, não explica senão aquilo que é dado no mundo exterior e na própria consciência e contenta-se assim em abarcar a essência do mundo na sua conexão íntima com ele próprio. ${ }^{4}$

Questões transcendentes, tais como a origem da vontade e a sua destinação ao objetivar-se, são afastadas por ultrapassarem a capacidade de nosso intelecto. Se há conhecimento, este é puro instrumento a serviço da vontade: o conhecimento é pois o do fenômeno, e o mundo só como tal é cognoscível; é por nós mesmos, pela análise de nossa própria consciência que podemos conhecer o que se manifesta para, depois, armados dessa chave da essência do mundo, decifrar o conjunto dos fenômenos e compreender seu encadeamento. Nas palavras do filósofo: "A essência das coisas, aquém ou alem do mundo e portanto além da vontade, está fechada a nosso exame". ${ }^{5}$ Ao expor os limites de sua filosofia, Schopenhauer pretende mostrar que permanece nos limites traçados pela crítica, considerando-se assim um "discípulo de Kant", por sinal "o mais fiel de todos"6.

Numa carta ao discípulo Frauenstädt, de 21 de agosto de 1852 , Schopenhauer o censura com dureza por nada ter compreendido do verdadeiro espírito de sua filosofia; clama ter sido em vão a sua advertência para que Frauenstädt não buscasse a coisa em si na "Cucolândia das nuvens", mas sim nas coisas do mundo, e ousasse ainda apontar uma contradição entre a coisa em si e seu conceito. ${ }^{7}$ Para o mestre, o conceito de coisa em si de Frauenstädt, como exprimindo aquilo que é imperecível, o ser primeiro, eterno e incriado, de fato é algo compatível com o Absoluto e o Deus para ele já suprimido anteriormente por Kant. Os disfarces com que ele aí se apresenta já teriam sido roubados do guarda-roupa de Kant, a saber, o supra-sensível ou o postulado da razão prática.

\footnotetext{
${ }^{4}$ Idem, p. 821.

${ }^{5}$ Idem, p. 824

${ }^{6}$ Schopenhauer, A. Sämtliche Werke, vol. I, p. 563.

7 Schopenhauer, A. "Deux Lettres". In: Cahiers de l' Herne. Paris: 1997, p. 248.
} 
Minha filosofia jamais fala da Cucolândia das nuvens, mas do mundo cá embaixo: quer dizer que é imanente e não transcendente. Decifra o mundo sob nossos olhos como hieróglifos, cuja chave encontrei na vontade. Ela mostra o encadeamento de suas partes. Ensina o que é o fenômeno e o que é a coisa em si. Mas tal coisa em si só o é relativamente, isto é, na sua relação com o fenômeno; e o fenômeno só é tal em relação à coisa em si. Mas o que é essa coisa em si fora dessa relação, eu nunca o disse, porque disso nada sei; mas é nela que está o querer-viver. A negação do querer-viver não é o aniquilamento de um objeto ou de um ser, mas um simples não-querer... ${ }^{8}$

Em suma, esse querer para Schopenhauer nada tem a ver com a matéria como permanência de uma substância. Tendo descartado a definição da coisa em si como o Absoluto, Schopenhauer indica ao discípulo que o conceito de matéria o definiria com mais precisão, pois Ihe daria uma justificação empírica. Ora, Schopenhauer queixa-se de que Frauenstädt já tenha esquecido a aprovação que dera antes a essa idéia, e que assim, com esse conceito de Absoluto ora apresentado, tenha-se extraviado, como seria de se esperar, num supra-sensível. Schopenhauer frisa que é só para nós que a supressão do querer é uma passagem para o Nada, já que não se trata da aniquilação de um ser - pois a coisa em si não significa um ser, mas sim uma atividade da vontade, o querer-viver. Após corrigir a interpretação de Frauenstädt, Schopenhauer deseja-Ihe uma boa viagem para a Cucolândia das nuvens, declarandose cansado de desfazer os mal-entendidos de seu interlocutor.

A sua interdição da transcendência é tão forte que, na Crítica à filosofia kantiana, Schopenhauer censura Kant pela definição de metafísica, dada no § 1 dos Prolegômenos, como ciência do que está além da experiência. Kant se teria equivocado ao aceitar uma falsa etimologia da palavra metafísica, como "além da física", e Schopenhauer alega que, com isso, Kant teria perdido a melhor e mais fidedigna fonte desse conhecimento, a saber, a experiência externa e interna no ponto em que

\footnotetext{
8 Idem, p. 249.
} 
se cruzam, isto é, no corpo. A metafísica do corpo e da vontade, como imanente, é que poderá dar esclarecimentos sobre o mundo, excluindo uma vontade ou uma inteligência ordenadora fora dele. Ao dizer que $o$ pensamento da morte leva à metafísica, Schopenhauer tem o cuidado de grifar a palavra metafísica, pois, como consolo e promessa de uma vida futura, nada mais seria que ilusão.

No sistema de Schopenhauer, metafísica significa indubitavelmente não um conhecimento que ultrapasse os limites do mundo, mas algo capaz de esclarecer o que nele acontece, a saber, seus fenômenos. Assim teremos, por exemplo, uma metafísica do amor sexual e uma metafísica da música. Mas a metafísica é tarefa do filósofo, pois nela não se trata de singularidades, mas daquilo que é geral e fundamental.

O filósofo não apresenta a própria vida, mas sim os pensamentos acabados que dela são extraídos e exige então que seu leitor pense do mesmo modo, tão longe como ele. Por isso seu público é tão pequeno. ${ }^{9}$

Para pensar a morte filosoficamente tem-se que superar duas alternativas falsas: a de que a morte seja uma negação absoluta e a que admite uma vida imortal. Não se trata de encontrar um ponto de equilíbrio entre elas, mas de afastá-las como enganadoras, observando-as de um ponto de vista mais alto, o filosófico..$^{10}$ Enquanto o senso comum tem uma visão singular e interessada das coisas, o filósofo observa-as no seu todo, buscando esclarecer sua gênese.

Na $1^{\text {a }}$. edição do Mundo, no $§ 54$, Schopenhauer nos fala da morte como ilusão, o nascer e perecer atingindo apenas o indivíduo e deixando intocada a espécie, como Idéia ou objetidade da Vontade. Seu pensamento está aí, em 1818, mais voltado para as noções de afirmação e de negação da vontade, núcleo de sua ética, que é desenvolvida na $4^{a}$. parte do Mundo. A pertinência do homem à natureza, expressão da vontade que é sinônimo do querer-viver, pode levar quem desconhe-

${ }^{9}$ Schopenhauer, A. Sämtliche Werke, vol. V, p. 11.

${ }^{10}$ Schopenhauer, A. Sämtliche Werke, vol. I, p. 592. 
ce ainda as agruras contínuas da existência a afirmá-la com ânimo vital, e deleitar-se com seus prazeres, mesmo tendo que assumir de bom grado suas deficiências e dores. Essa atitude é a da afirmação da vida, possível para quem tem um conhecimento, "não apenas abstrato, mas íntimo", de ele próprio ser a Vontade, estando com ela sempre no presente e vendo o passado e o futuro como miragens vazias, formas que cabem apenas ao fenômeno. ${ }^{11}$

Schopenhauer cita, num gesto de Aufklärer, o poema "Prometeu" de Goethe, afirmação do querer do homem e de seus atos diante de um Zeus despótico: "Aqui me ponho a formar o homem a minha imagem, da mesma espécie que eu, para sofrer, chorar, sentir prazer e alegrar-se, sem fazer, como eu, caso de Ti”.

A idéia de permanência do mundo no tempo mesmo após nossa morte não poderia ser um consolo eficaz, trazendo em si uma contradição, a ausência de tempo para a vontade. De fato, a verdadeira negação do querer-viver surge da atitude oposta, a saber, a ausência de qualquer estímulo que possa produzir efeito no ânimo, caso em que o conhecimento do mundo na sua essência se transforme num quietivo para a vontade. Aqui se expressa a diferença entre a morte do indivíduo, como evento fenomênico vivido independentemente de qualquer conhecimento, mesmo intuitivo, e a sua negação metafísica, em que a vontade se reconhece ao voltar-se sobre si mesma. Nesse capítulo, põe-se em relevo a inutilidade do suicídio, que nada mais faz que aniquilar o indivíduo, deixando intacto o querer-viver. Não poderíamos ver nesse ato extremo uma escolha diante do conhecimento da vida como sofrimento contínuo? Porém, a decisão baseada em tal escolha seria vã, pois o principal motivo do suicídio, no ver de Schopenhauer, seria ou o desespero diante da impossibilidade de realizar um desejo, ou a presença obsedante e angustiante de um motivo ou de um estímulo do querer-viver, mesmo que irrealizável. A visão que Schopenhauer tem do suicídio parece expressar-se simbolicamente no poema de Appolinaire "O suicida"12, um

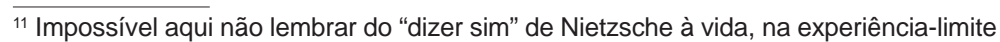
do eterno retorno, se pensarmos tal eterno como presente.

12 Appolinaire, G. "O suicida". Traduzido do russo por Iddinio Rosseto. (Extraído da própria sinfonia de Schostakovich.)
} 
dos textos que Schostacovich escolheu para a sinfonia no. 14, que tem por tema a morte:

Q'kmrahhu' - O suicida

Três lírios... Três lírios...

Três lírios em meu túmulo sem cruz.

[Três lírios borrifados pelo ouro

que o vento frio dispersa...

...e regados apenas pela

chuva copiosa do céu escuro.]

$E$, qual cetros ameaçadores...

eles têm uma beleza solene.

Um, cresce da minha ferida...

e quando um raio de sol o toca...

ergue-se ensangüentado:

é o lírio da angústia.

[Três lírios... Três lírios...

Três lírios em meu túmulo sem cruz.

Três lírios borrifados pelo ouro

que o vento frio dispersa.]

O outro cresce do meu coração

que sofre, atroz...

no leito onde os vermes o devoram.

O terceiro germina

dilacerando minha boca.

Eles crescem solitários em meu túmulo...

Nos complementos ao Mundo em sua $2^{a}$. edição, no $\S 41$, Schopenhauer retoma a reflexão metafísica sobre a morte. O temor da morte e o pensamento da finitude estariam, pois, na gênese da metafísica e da religião. O autor parte de considerações empíricas, para buscar no umbral das considerações metafísicas, através da aparência da perpétua aniquilação, a eterna presença da vida. É nesse texto complementar que Schopenhauer resolve o duplo equívoco dos homens 
ao pensarem a morte: ou como aniquilação, ou como imortalidade. E é por desconhecimento da distinção entre o sujeito do conhecer, quem suporta o mundo nas suas representações, e o sujeito do querer, a própria essência do mundo, que o homem tem, diante da morte, tais concepções extremas e opostas.

Tanto o homem quanto o animal experimentam o medo da morte. O medo de morrer é o maior dos medos, visto como o maior dos males. O conhecimento e a reflexão não participam como causa desse temor, mas talvez, ao avaliar a vida e seus males, dêem preferência ao nãoser. A fonte desse terror irracional é a cegueira do querer-viver. Para o intelecto o não ser depois da morte equivale por certo ao não ser antes da vida. $E$ por que não ocorre a ninguém lamentar o não ter existido? ${ }^{13} \mathrm{O}$ que era eu antes de nascer? E depois da morte? O que serei? Metafisicamente, isto é, vendo através do véu da Maia da individuação, fui e serei sempre eu.

A primazia da vontade sobre o intelecto, produto do cérebro, faz da consciência algo secundário, dependente do impulso do querer. Pois a consciência não é autônoma, dependendo de um algo que é visado: ela é um órgão que deve velar em primeiro lugar pela sobrevivência, mas como tal não sobrevive ao organismo a que pertence. $O$ quererviver, como o primário que se expressa em toda natureza, fica intocado pela morte do indivíduo. À vontade, o que interessa mais de perto é a espécie, sua objetividade primeira, e por isso mesmo a sexualidade desempenha um papel tão relevante na vida do indivíduo. É por meio dela que ele se encontra a serviço da espécie, sendo o amor uma astúcia da Vontade para que ela se perpetue - a crença de Schopenhauer na fixidez das espécies, coincidente com a dos fisiólogos seus contemporâneos, Cabanis e Bichat, reforça sua teoria. O indivíduo, enquanto fenômeno, submetido ao princípio de razão, que se expressa no devir pela causalidade, tempo e espaço, é uma mera ilusão; sua essência está no corpo enquanto manifestação da vontade. Individuo e corpo desaparecendo na morte, o querer-viver está sempre no presente, sendo o passado e o futuro abstrações intelectuais, que tocam apenas ao indivíduo.

\footnotetext{
${ }^{13}$ Schopenhauer. Sämtliche Werke, vol. II, p. 593 e ss.
} 
Ainda assim, o problema da individualidade não é de fácil solução, pois em relação ao homem Schopenhauer, inspirando-se em Kant, fala de um caráter inteligível e de uma Idéia para cada ser humano. Michel Piclin cita, a propósito, passagens do texto sobre a morte em que Schopenhauer fala da vida que se repete em inúmeros indivíduos, como se todos fossem um único, mas sem que saibam sê-lo. Ora, o comentador acredita ver nesse trecho a confirmação da indestrutibilidade do caráter inteligível individual, porém parece-me que essa interpretação perde seu apoio quando Schopenhauer, logo a seguir, fala de uma possível vantagem da morte, a possibilidade de mudança do caráter. A saber: se no correr da minha vida só posso ser eu mesmo, querendo o que quero, justamente por ter este caráter e não outro, só depois de minha morte, ao nascer outro indivíduo, surgiria a oportunidade de ser outro que não eu mesmo. Ora, isto põe em causa a argumentação de Piclin. ${ }^{14}$ Porém, ele mesmo pergunta a seguir pelo fundamento dessa individualidade. Como pensá-la fora do princípio de individuação? O caráter numênico não podendo ser apreendido pelo conhecimento por não estar submetido à causalidade, e portanto ao espaço e ao tempo, não poderia ser individualidade, já que esta implicaria como correlato uma pluralidade. Herança de Kant, que Schopenhauer não poderia assumir sem contradição? Schopenhauer no entanto afirma que

a individualidade não é apenas inerente ao princípio de individuação, mas é também inerente à vontade. E pode-se ainda perguntar: até que profundidade da essência em si do mundo vão as raízes da individualidade? A que se pode talvez responder: elas vão tão longe quanto a afirmação do querer-viver, e detêm-se onde começa a sua negação; pois surgiram com a sua afirmação. ${ }^{15}$

Por que apenas na afirmação da vontade? A isto se poderia responder que a vontade, uma vez afirmada, já se espelharia no mundo e

${ }^{14}$ Piclin, M. "Le problème de la conscience et de la mort dans la philosophie de Schopenhauer". In: Cahiers de l' Herne. Paris: 1997.

${ }^{15}$ Schopenhauer, A. Sämtliche Werke, vol. II, p. 822. 
seria representação. Ou seja, ao afirmar a vontade seríamos já indivíduos, pois a estes cabe a escolha entre as atitudes de negar ou afirmar, e tal escolha, por depender de motivos, pertence ao intelecto. Assim, o fim natural do indivíduo seria a morte física, e depois dela nada mais permaneceria a não ser o querer-viver da espécie.

O morrer deve ser visto como o fim próprio da vida, em cujo instante é decidido tudo aquilo que foi apenas preparado e começado em todo processo vital. A morte é o resultado, o resume da vida ou a soma concentrada expressa de uma só vez todo o ensinamento que a vida deu, de modo isolado e parcial, a saber o de que o esforço total, de que a vida é o fenômeno, foi algo em vão, inútil, contraditório,do qual se livrar é uma redenção. ${ }^{16}$

Ao pensar a morte como fim último do indivíduo introduz-se o finalismo no pensamento do filósofo? Esse ponto merece uma reflexão mais detida, pois na crítica à filosofia de Kant Schopenhauer vê o mérito do finalismo do "como se" - isto é, admissível só onde necessário para tornar possível o estudo do organismo, onde falha o princípio do mecanismo. Não há nem haverá um Newton do ramo de relva, tal como o disse Kant. A vontade é um impulso sem fundamento e sem alvo, e pensar numa finalidade constitutiva que guiasse o querer-viver seria contrário à própria noção de vontade, que é ímpeto cego. Se finalidade houver, só poderá ser pensada na natureza enquanto manifestação da vontade, que se organiza em graus - do inorgânico ao orgânico, de espécie a espécie. Mas tal finalismo se desenvolveria na temporalidade? Essa leitura parece ser contrária à concepção da vontade e de suas manifestações na simultaneidade. Aliás, Schopenhauer critica Lamarck quando este, ao supor um animal primordial que se desenvolveria pelas suas necessidades de conservar-se, estaria condenando tal ser a sucumbir, pois sua adaptação ao meio poderia dar-se tarde demais. Mantém-se no entanto uma certa ambivalência no que se refere ao estatuto da finalidade, pois na obra $A$ vontade na natureza ele diz:

\footnotetext{
${ }^{16}$ Idem, p. 817.
} 
ponho pois em primeiro lugar a vontade como coisa em si absolutamente originária ; depois seu fenômeno, sua objetivação, o corpo; em terceiro lugar o conhecimento, como simples função deste corpo - essa parte é a objetivação do querer conhecer, a vontade precisando do conhecimento para chegar ao seu fim. ${ }^{17}$

Se interpretarmos tal texto ao pé da letra, teremos de dar razão a Goldschmidt ${ }^{18}$ em seu texto sobre o finalismo em Schopenhauer, onde afirma que ele não é apenas regulativo, tal como em Kant, mas constitutivo. Freud também parecia ver assim a finalidade em Schopenhauer, quando ao falar de dois processos vitais contrários, reconhecendo neles as duas pulsões - de vida e de morte -, afirma que para o filósofo a morte é o resultado próprio e a finalidade da vida, a pulsão sexual a corporificação da vontade de viver. ${ }^{19}$ Freud vê-se assim, inesperadamente, adentrando o porto da filosofia de Schopenhauer, ao descobrir o dualismo das pulsões. Freud cita também o texto $A$ aparente intencionalidade no destino do indivíduo, em que Schopenhauer propõe a vontade como sendo quem secretamente dirige o nosso destino. Mas esse querer, além da consciência, manifesta-se nos seus fenômenos, "cada homem o contém de modo bem individual e único, como um ato individualizado dele". ${ }^{20}$ Cada homem tem seu próprio caráter, cada um terá sua própria morte, ou melhor, "escolherá", mesmo sem o saber, sua própria morte. A morte é o alvo final da existência temporal dos indivíduos e cada um deles é conduzido para ela, "à sua maneira e muitas vezes aos poucos, por amplos desvios". Se cada um tem sua própria morte é porque a escoIheu. ${ }^{21} \mathrm{O}$ reconhecimento do corpo como marca essencial do indivíduo, e a de suas ações como expressando os atos da vontade, faz com que o caminho para a morte seja facilitado pela infelicidade e pelo sofrimento, e barrado pelo prazer e felicidade. A luta entre os impulsos opostos manifesta-se no corpo como fenômeno imediato da vontade, que, ao

\footnotetext{
17 Schopenhauer, A. Sämtliche Werke, vol. III, p. 340.

${ }^{18}$ Goldschmidt, V. "Schopenhauer et Lamarck". In:

Écrits, vol. 2. Paris: Vrin, 1984.

${ }^{19}$ Freud, S. "Jenseits des Lusts Princips". In Studiensausgaben, vol. III. Frankfurt, S.Fischer Verlag, 1975, p. 258-9.

${ }^{20}$ Schopenhauer, A. Sämtliche Werke, vol. IV, p. 272

${ }^{21}$ Idem, ibidem.
} 
invés de ser uma e fechada em si mesma, apresenta-se cindida, e pois fonte de uma luta em todos os níveis da natureza, desde a matéria inerte, por exemplo - luta entre peso e resistência -, até chegar ao homem e seus dois impulsos opostos - a conservação e a destruição de si. Essa luta surda entre os impulsos passa-se fora do teatro da consciência, pois embora as decisões sejam racionais, tomadas através de motivos apresentados pelo intelecto, quem dá a última palavra é o querer-viver que tem seu foco na sexualidade..$^{22}$ Essa antecipação do papel condutor da sexualidade é um ponto fundamental também reconhecido por Freud num texto de 1925, As resistências à psicanálise. Descoberta de um filósofo ousado, antecipando a confirmação da pesquisa científica? Ou algo presente nos ares da época? ${ }^{23}$

Para o filósofo de Frankfurt, a vontade se manifesta na natureza numa gradação de Idéias, as objetivações da vontade, que vão da matéria inanimada, com suas forças físicas e químicas, para o mais perfeito, o orgânico, numa luta entre elas para se apossarem da matéria. As Idéias mais perfeitas, ao triunfarem sobre as imperfeitas, ainda guardam em si estas últimas, e o combate se perpetua com a resistência das formas vencidas. A posse mais antiga do organismo pelas forças inferiores faz com que elas continuem a lutar, explicando-se assim a saúde, a doença e a fadiga. A vitória final das forças inferiores no curso do organismo é a sua morte, o restabelecimento do estado inorgânico. A morte é para o filósofo uma "crise" no sentido mais forte da palavra, o que ele chama de Weltgericht, tribunal do mundo. ${ }^{24}$

Ora, quando Freud fala sobre a pulsão de morte na quarta das Novas conferências, refletindo sobre o caráter conservador da pulsão de autodestruição, ele admite a hipótese de que, se a vida surgiu da matéria inanimada, teve de surgir uma pulsão que restabelecesse o es-

\footnotetext{
${ }^{22}$ Idem. Ver também o segundo livro do Mundo como Vontade e Representação, cap. 18 e ss.

${ }^{23}$ Essa "antecipação filosófica" de uma descoberta científica é como Freud explica o papel da sexualidade em Schopenhauer. Em contrapartida, não se trata, a nosso ver, de mera antecipação genial, mas de uma idéia baseada no pensamento sobre o organismo na evolução da biologia, que foi exposta, em direções diferentes, porém com sentido semelhante, em Schopenhauer e Freud.

${ }^{24}$ Do grego Krisis: decisão, mudança decisiva, que vem do verbo krinein, separar. Tribunal que profere a sentença final sobre o mundo ou a vida do indivíduo.
} 
tado anterior. Pode-se considerar a autodestruição como manifestação da pulsão de morte que se encontra em todo processo vital, ao lado da pulsão de vida. E "da colaboração e da luta entre as duas pulsões surgem os fenômenos da vida aos quais a morte põe fim". ${ }^{25}$

Mas Freud recusa-se a chegar à conclusão de Schopenhauer quando este vê na morte o fim próprio da vida. Afirma, ainda nas Novas conferências, a presença da vida ao lado da morte. E deixa em aberto para futuras investigações "como ambas se mesclam no processo da vida e como a pulsão de morte é levada a coadjuvar com os propósitos de Eros, sobretudo no voltar-se para o exterior como agressão."26

Para Schopenhauer, é o próprio querer-viver que se expressa agressivamente na luta pela posse da matéria, e o impulso para a morte já faria parte integrante das forças auto-destrutivas presentes no organismo. Se a morte é o fim da vida individual, o querer-viver cósmico só pode afirmar-se, e sua negação completa no campo ético, a morte simbólica do todo, só se dá como exceção. Também no indivíduo, no que toca à moral, encontramos, como já dito, duas alternativas: a afirmação da vida apesar de todos os males e a sua negação pelo ascetismo, que não é vista como mera destruição, mas como ato libertador que aponta para um desconhecido e indizível.

Seria essa negação metafísica, inteiramente distinta da morte natural, a resposta do filósofo à sua musa? Ou, como diriam os seus leitores - Nietzsche e Horkheimer por exemplo -, sua resposta aos tempos sombrios? ${ }^{27}$

\footnotetext{
${ }^{25}$ Freud, S. "Neue Folge der Vorlesung zur Einführung in der Psychoanalyse". In: Studienausgabe, vol. I, p. 540. (Nuevas lecciones introdutórias al psicoanalisis. Madrid, Ed Nueva, 1981, p. 3161.)

${ }^{26}$ Idem, Ibidem. (Idem, p. 3162)

${ }^{27}$ Nietzsche, numa das Considerações Extemporâneas, "Schopenhauer Educador", atribui a visão pessimista de Schopenhauer aos tempos de "décadence" em que este viveu. O tempo "madrasta" teria feito o filósofo interpretar o mundo de acordo com o que via em seu entorno: as caras feias e abatidas. Por sua vez Horkheimer, em "Schopenhauer e a sociedade", vê a filosofia de Schopenhauer como protesto contra a sociedade de seu tempo, afirmando que a concepção de mundo e sociedade do filósofo só poderia ter-se dado numa sociedade eminentemente repressora , à qual Schopenhauer não fazia qualquer concessão.
} 


\section{BIBLIOGRAFIA:}

FREUD, S. "Jenseits des Lusts Princips". In: Studiensausgaben, vol. III. Frankfurt: S.Fischer Verlag, 1975a.

"Neue Folge der Vorlesung zur Einführung in der Psychoanalyse". In: Studiensausgaben, vol. III. Frankfurt: S.Fischer Verlag, 1975b.

1981.

Nuevas lecciones introdutórias al psicoanalisis. Madri: Ed Nueva,

GOLDSCHMIDT, V. "Schopenhauer et Lamarck". In: Écrits, vol. 2. Paris: Vrin, 1984.

HORKHEIMER, M."Schopenhauer y la sociedad". In: Sociologica. Madrid:

Ediciones Taurus, 1971.

NIETZSCHE, F. Considerações Extemporâneas. In: Coleção Os Pensadores, vol. Nietzsche. São Paulo: Abril, 1974.

PICLIN, M. "Le problème de la conscience et de la mort dans la philosophie de Schopenhauer". In: Cahiers de l'Herne, Paris: 1997.

SCHOPENHAUER, A. Sämtliche Werke. Darmstadt: Ed Löneysen WBG, 1974. "Deux Lettres". In: Cahiers de l'Herne. Paris: 1997. 
